\title{
O monstro invisível: o abalo das fronteiras entre monstruosidade e humanidade
}

Juliana Ciambra Rahe Bertin

UFMS/CPTL

\begin{abstract}
Resumo
Este trabalho tem como objetivo investigar como o monstro moderno se apresenta na literatura. No deslocamento do monstro físico para o monstro moral, identificado por Foucault, a monstruosidade deixa de ser visualmente identificável no aspecto físico. Pretendemos mostrar como outros atributos que integram a configuração da monstruosidade também passam por transformação, pontuando nossa análise com exemplos de textos literários da literatura inglesa do século XIX e de narrativas literárias brasileiras de Machado de Assis, Rubem Fonseca e Lourenço Mutarelli. Nosso objetivo é apontar como a atualização das características dos monstros acaba aproximando tais figuras cada vez mais do humano, em um deslocamento que embaça as fronteiras que separam nós e eles, identidade e alteridade, humanidade e monstruosidade.
\end{abstract}

Palavras-chave: Monstruosidade; Monstro Comportamental; Literatura Brasileira.

\begin{abstract}
This study aims to investigate how the modern monster presents itself in literature. In the displacement of physical monster for moral monster, identified by Foucault, hybridity that composes such creatures can no longer be visually identified in physical appearance. In the same motion, we intend to show how other attributes that make up the configuration of monstrosity also change, presenting in our analysis with examples of literary texts of English literature of the nineteenth century and Brazilian literary narratives by Machado de Assis, Rubem Fonseca and Lourenço Mutarelli. Our goal is to point out how the update of the characteristics of monsters approaches such figures to human, in a shift that blurs the boundaries between us and them, identity and otherness, humanity and monstrosity.
\end{abstract}

Keywords: Monstrosity; Behavioral Monster; Brazilian literature. 


\section{Introdução}

Monstros costumam apresentar traços recorrentes que permitem traçar uma espécie de morfologia de tais criaturas. Embora se apresentem sob diferentes máscaras, as características que envolvem a monstruosidade permanecem basicamente as mesmas, sendo centrais para a investigação da monstruosidade elementos como: espaço geográfico, impureza, ameaça, ambivalência afetiva, prazer, poder e liberdade.

No entanto, com a passagem - proposta por Foucault - do monstro físico para o monstro moral as particularidades que identificam tais criaturas sofrem algumas alterações. A monstruosidade que reside na forma de se comportar, e não no aspecto físico, pode ser verificada em narrativas cujos personagens, não tendo suas bases fincadas no sobrenatural, se aproximam de um contexto ordinário. Em vez de zumbis, lobisomens e vampiros, nos interessa a composição da monstruosidade de personagens mais próximos da "realidade".

Assim, observando as características monstruosas de seres extraordinários em um mundo ordinário - como a criatura de Frankenstein, o conde Drácula e o duplo Hyde, no qual Jekyll se transforma - veremos, num segundo momento, o que se altera quando nos detemos sobre seres aparentemente ordinários em um mundo ordinário - como algumas personagens que povoam a literatura brasileira desde o realismo até a contemporaneidade: Fortunato, do conto "A causa secreta", de Machado de Assis; o narrador-personagem dos contos "Passeio Noturno (Parte I)" e "Passeio Noturno (Parte II)", de Rubem Fonseca; e o protagonista do romance $O$ cheiro do ralo, de Lourenço Mutarelli.

\section{A configuração do monstro}

1. GILMORE, David D.

Monsters: evil beings, mythical beasts and all manners of imaginary terror, 2003, p. 192.
Os monstros estão geograficamente associados ao conceito de fronteira. Eles habitam um espaço periférico, marginal, em todas as tradições culturais, "[...] [they] emerge from a kind of metaphorical exile, from borderline places. [...] whatever the people in a particular culture demarcate as wilderness, as noncultural space, as unexplored territory, there are monsters"".

Luiz Nazário aponta a origem do monstro no Além. Segundo o autor, ele surge:

[...] de uma cidadezinha isolada, da selva primitiva, de uma ilha solitária, das profundezas do mar, do sono eterno, de 
um mundo desconhecido, do abismo sem fim, de uma civilização extinta, do passado remoto, de lagoas estagnadas, do futuro imprevisível, de um pântano ermo, de poços abandonados, do reino das trevas, de laboratórios secretos - numa palavra: do Inconsciente. ${ }^{2}$

Os adjetivos de que o autor se vale para qualificar tais espaços (como isolado, solitário, desconhecido, remoto, ermo, abandonado) apontam para aquilo que permanece escondido, não revelado ou reprimido, em suma, fora do conhecimento.

Essa mesma noção se apresenta nas reflexões de Timothy Beal, segundo o qual o habitat que compõe a monstruosidade estabelece os limites entre o conhecido e o desconhecido, reforçando a noção de monstro como figura intersticial que demarca a fronteira dentro/fora:

\begin{abstract}
Maps plot the lay of the land, making it known and knowable. In the process they also mark off what is unknown along their edges and within their deepest seas. On ancient maps, the terra incognita, or "unknown territory", was sometimes marked by images or fantastical monsters accompanied by textual warning, the most famous being bic sunt dracones, "here be dragons". These monstrous figures indicate regions of dangerous uncertainty. They show where the limits of knowing are. They dwell on the threshold between the known and the unknown, this world and its other worldly beyond. These monsters are interstitial figures, markers of the inside/outside. ${ }^{3}$
\end{abstract}

O espaço do Drácula, por exemplo, é a Transilvânia primitiva, selvagem e exótica: "As the name of the region suggests (trans + silva, 'across' or 'beyond the wilderness'), this region is present as an unstable and dislocating threshold space between the occidental and the oriental"'4. À proximidade do castelo do conde, as descrições das personagens revelam o caráter desconhecido e fronteiriço do espaço: "Existia algo de selvagem e insólito naquele lugar" ; " tudo é rochoso, escarpado, selvagem, como se aqui fosse o fim do mundo".

Outra característica da figura monstruosa é a impureza. Jeffrey Cohen, no ensaio "A cultura dos monstros: sete teses", conceitua os monstros como os arautos da crise de categorias. Segundo o autor, o monstro se recusa a fazer parte da ordem classificatória das coisas, "ele desintegra a lógica silogística e bifurcante do 'isto ou aquilo', por meio de um raciocínio mais próximo do 'isto e/ou aquilo"'?

Uma categoria mista, o monstro resiste a qualquer classificação construída com base em uma oposição meramente binária, exigindo, em vez disso, um "sistema" que permita
2. NAZÁRIO, Luiz. Da naturez̧a

dos monstros, 1998, p. 22.

3. BEAL, Timothy K. Religion and its monsters, 2002, p. 194.

4. Ibidem, p. 126.

5. STOKER, Bram. Drácula, 2014, p. 594.

6. Ibidem, p. 583.

7. COHEN, Jeffrey. "A cultura dos monstros: sete teses", 2000, p. 32. 
8. Ibidem, p. 31.

9. CARROLL, Noël. A filosofia do horror ou os paradoxos do coração, 2000 , p. 39.

10. Ibidem, p. 51 .

11. SHELLEY, Mary.

Frankenstein ou o Prometeu moderno, 2011, p. 134.

12. Ibidem, p. 240 a polifonia, a reação mista (diferença na mesmidade, repulsão na atração) e a resistência à integração. ${ }^{8}$

Monstros são considerados não apenas impuros, mas também imundos e repugnantes. A ameaça e o medo que eles despertam normalmente aparecem associados à repugnância, à náusea e à repulsa. Segundo Carroll, frequentemente monstros são "coisas pútridas ou em desintegração, ou vem de lugares lamacentos, ou são feitos de carne morta ou podre, ou de resíduo químico, ou estão associados com animais nocivos, doenças ou coisas rastejantes"?.

$\mathrm{O}$ autor - partindo do estudo Purity and danger, de Mary Douglas - associa impureza com transgressão ou violação de esquemas de categorização cultural. Para Douglas, devido à dificuldade de categorização, são consideradas impuras as criaturas rastejantes do mar, como a lagosta (já que rastejar é uma característica de animais terrestres); insetos alados com quatro patas (uma vez que pernas são características de animais terrestres, mas essas criaturas voam); e também resíduos orgânicos como fezes, cuspe, vômito e sangue (que tornam ambíguas as oposições fora/dentro, eu/não eu, vivo/morto). Seguindo essas reflexões, Carroll afirma que os monstros são impuros por serem categoricamente intersticiais, contraditórios, incompletos ou informes. Daí vem a forma normalmente usada para mencionar os monstros:

[...] o recurso frequente à referência por pronomes como "isso" e "eles" sugere que essas criaturas não podem ser classificadas segundo nossas categorias estabelecidas. Além disso, essa interpretação também é corroborada pela frequência com que se diz que os monstros do horror são indescritíveis ou inconcebíveis. ${ }^{10}$

A criação de Frankenstein, monstro a que não se dá nome, é descrita como ser "dotado de uma forma física horrendamente deformada e repulsiva" 11 . A criatura, a quem o cientista compõe a partir de partes de cadáveres, viola as categorias vivo/ morto e o aspecto hediondo resultante de tal criação é motivo de horror e repugnância.

Entrei na cabina onde estava o corpo de meu admirável e desgraçado amigo. Sobre ele, debruçava-se um ser que não encontro palavras para descrever - de estatura gigantesca, mas desajeitado, e de proporções distorcidas. Ao inclinar-se sobre o caixão, sua face era encoberta por longas mechas de cabelos emaranhados; mas uma de suas compridas mãos estava estendida e tinha a cor e a textura iguais às de uma múmia. [...] Eu jamais contemplara algo tão horrível quanto aquele rosto, a um tempo repulsivo e apavorante. ${ }^{12}$ 
Monstros provocam medo e terror, mas também admiração e reverência. Os monstros despertam uma ambivalência afetiva ou, nas palavras de Cohen, repulsão na atração. Segundo Beal, a experiência do horror em relação ao monstro é frequentemente descrita como uma combinação de medo e desejo, "simultaneously awesome and awful - a feeling captured in the older spelling, 'aweful', which still retains its sense of awe"13.

Em Drácula, a reação das personagens diante de Lucy, cuja beleza pareceu aumentar após sua transformação em vampira é de "fascínio, espanto e medo". Por outro lado, Drácula exerce, principalmente em Lucy, um poder de atração: "Sei que, por algum motivo, senti o desejo irresistível de vir até aqui, ao cemitério deserto. Mas, ao mesmo tempo, também sentia medo de alguma coisa - não sei o quê"14. E, ao relatar o episódio em que é mordida pelo vampiro, os termos usados por Lucy para retratar o que sentiu colocam em cena a ambivalência que compõe o monstro: "me senti envolvida em algo ao mesmo tempo doce e amargo, que me cercava por todos os lados"15.

Analisando serial killers como monstros humanos, Alexa Wright (2013) questiona a razão pela qual tais criminosos alcançam o status de celebridade. Um dos fatores apontados pela autora diz respeito ao poder desses indivíduos, que os transforma em uma figura mítica - metade real, metade ficcional, onipotente, onisciente e onipresente e, por isso, pode ser empolgante e envolvente. Segundo Noël Carroll, parte da sedução dos monstros está ligada ao poder que eles possuem e à admiração que tal atributo desperta. No entanto, levando em conta o gênero horror artístico, sob o qual repousa o trabalho de Carroll, o sentimento de atração que os monstros exercem pode ser mais bem explicado pela curiosidade que despertam justamente pelo fato de serem categoricamente intersticiais. Segundo o autor,

Seu desvio em relação aos paradigmas do nosso esquema de classificação chama imediatamente nossa atenção. É uma força de atração; atrai a curiosidade, isto é, torna-os curiosos; convida à interrogação sobre suas surpreendentes propriedades. Queremos ver o incomum, ainda que ele seja, ao mesmo tempo, repelente.

Os monstros [...] são repelentes por violar categorias vigentes. Mas, pela mesmíssima razão, também chamam nossa atenção. São atraentes, no sentido de provocar interesse, e são a causa, para muitos, de uma atenção irresistível, mais uma vez, justamente por violar categorias em vigor. ${ }^{16}$

Essa forma de atração é despertada em Dr. Lanyon, que descreve o sentimento que Hyde provoca como uma "curiosidade desagradável”. É interessante notar que a utilização dessas palavras combinadas coloca em cena, mais uma vez, a ambivalência do monstruoso:
13. BEAL, Timothy K. Religion and its monsters, 2002, p. 7.

14. STOKER, Bram. Drácula, 2014, p. 199.

15. Ibidem, p. 199.

16. CARROL, Noël. A filosofia do horror ou os paradoxos do coração, 2000 , p. 267. 
17. STEVENSON, Robert

Louis. O médico e o monstro, 2011, p. 76-77.

18. COHEN, Jeffrey. "A cultura dos monstros: sete teses", 2000, p. 48 .

19. GILMORE, David D.

Monsters: evil beings, mythical beasts and all manners of imaginary terror, 2003, p. 12.

20. COHEN, Jeffrey. "A cultura dos monstros: sete teses", 2000 , p. 49.

21. NAZÁRIO, Luiz. $D a$

natureza dos monstros, 1998, p. 15.
É estranho relatar, mas esse ridículo vestuário estava longe de me fazer rir. Ao contrário, como havia algo de anormal e vil na essência da criatura que agora estava na minha frente - algo envolvente, surpreendente e revoltante -, essa nova disparidade parecia adaptar-se e reforça-la; de forma que a meu interesse na natureza e no caráter daquele homem foi adicionada uma curiosidade quanto a sua origem, sua vida, seu destino e sua posição no mundo. ${ }^{17}$

Para Cohen, a ambivalência afetiva provocada pelos monstros é explicada por outro atributo comum a tais criaturas: a liberdade:

Para que possa normalizar e impor o monstro está continuamente ligado a práticas proibidas. O monstro atrai. As mesmas criaturas que aterrorizam e interditam podem evocar fortes fantasias escapistas; a ligação da monstruosidade com o proibido torna o monstro ainda mais atraente como uma fuga temporária da imposição. [...] Nós suspeitamos do monstro, nós o odiamos ao mesmo tempo em que invejamos sua liberdade. ${ }^{18}$

Segundo Cohen, há uma relação entre a atração que o monstro provoca e a forma como ele se comporta: extrapolando os limites do permitido e despertando inveja justamente por isso. $\mathrm{O}$ autor identifica uma associação dos monstros com uma ideia de liberdade e libertação, uma vez que eles pautam suas condutas por suas próprias regras ou vontades e não sentem remorso ou medo de punição. Os tabus, a moral e nem mesmo os ordenamentos jurídicos que regem a sociedade os alcançam e eles agem sem se preocupar com os outros. "[...] [T]hey break the rules and do what humans can only imagine and dream of. Since they observe no limits, respect no boundaries, and attack and kill without compunction, monster are [...] the spirit that say 'yes' to all that is forbidden"19. Nesse sentido, os monstros são livres.

Essa falta de limitação que o monstro apresenta lhe confere uma noção de prazer. Ele é liberado de regras para satisfazer suas vontades - sejam elas relacionadas a práticas sexuais ou costumes sociais - sem se reprimir por moral ou pudores inculcados pela sociedade. "O monstro nos desperta para os prazeres do corpo, para os deleites simples e evanescentes de ser amedrontado ou de amedrontar - para a experiência da mortalidade e da corporeidade" 20 .

A hipótese de que o monstro encarna o princípio de prazer, válido somente para si, é confirmada por sua origem extraordinária: o monstro não tem pai, não está sexualmente identificado, sendo destituído de repressão, superego, complexo de Édipo, sentimento de culpa ou princípio de realidade. $^{21}$ 
Assim como liberdade e prazer, outro atributo monstruoso é o poder. Carroll aponta que:

Um fato notável acerca das criaturas do horror é que muitas vezes elas não parecem ter força suficiente para dobrar um homem feito. Um zumbi com um eczema ou com uma mão cortada parece incapaz de reunir forças suficientes para dominar uma criança de seis anos bem coordenada. No entanto, tais criaturas são apresentadas como irresistíveis. $^{22}$

Esses elementos podem ser observados em $O$ médico e $o$ monstro. A forma como Dr. Henry Jekyll descreve sua sensação ao transformar-se pela primeira vez em Edward Hyde pode ser tomada como exemplo da liberdade e do prazer a que os monstros estão associados:

Senti-me mais jovem, mais leve e fisicamente mais disposto. Em meu interior tornei-me consciente de uma impetuosa imprudência, da presença de um contínuo de imagens sensuais desordenadas, passando como um filme em minha imaginação; estava também ciente de uma diluição nas amarras da responsabilidade, de uma liberdade desconhecida mas, sem dúvida, nada inocente. Já ao primeiro sopro dessa nova vida percebi-me mais cruel, dez vezes mais cruel - vendido como um escravo a minha maldade original. E, naquele momento, tal pensamento teve o poder de me embriagar como o vinho. ${ }^{23}$

A possibilidade de praticar violência sob a forma física de Hyde garante imunidade a Jekyll, que pode cometer crimes sem enfrentar as consequências morais e legais, experimentando apenas o prazer que tal atitude desperta: "Cada ato e pensamento seu [de Hyde] era centrado nele mesmo. Com bestialidade voraz, sorvia prazer de todo e qualquer grau de tortura que aplicasse a outros; mostrava-se implacável como se fosse um homem de pedra"24. A transformação monstruosa provoca uma alteração no humor de Jekyll que sente "a coragem engrandecida, um desprezo pelo perigo, a dissolução das amarras da responsabilidade"25: em outras palavras, sente-se livre e poderoso.

Antigamente, um homem contratava bandidos para executarem seus crimes, protegendo, desse modo, sua própria pessoa e sua reputação. Fui o primeiro a fazê-lo por puro prazer. Fui o primeiro a poder passear diante dos olhos do público com a carga de uma sociável respeitabilidade e, no momento seguinte, como se fosse um menino, um estudante, despojar-me desse peso emprestado e lançar-me de cabeça no mar da liberdade. ${ }^{26}$
22. CARROLL, Noël. A filosofia do horror ou os paradoxos do coraşão, 1999, p. 53.

\section{STEVENSON, Robert}

Louis. O médico e o monstro, 2011, p. 85.

24. Ibidem, p. 89.

25. Ibidem, p. 97.

26. Ibidem, p. 88 . 


\section{Por uma nova morfologia do monstruoso}

27. CANGUILHEM, Georges.

"A monstruosidade e o monstruoso", 2012, p. 194.

28. FOUCAULT, Michel. Os anormais, 2010, p. 69.

29. Ibidem, p. 63
Alexa Wright parte das considerações de Michel Foucault em Os anormais - em contraposição às ideias desenvolvidas por Georges Canguilhem - para explicar a transição histórica do monstro morfológico para o monstro comportamental. Canguilhem argumenta que no final do século dezoito o monstro corpóreo começa a perder seu significado simbólico, uma vez que a expansão do pensamento científico passa a permitir um apagamento da deformidade física por meio da nomeação, classificação e explicação de suas causas. Com o avanço da ciência, que tornou possível criar monstros em laboratório, elimina-se a correspondência entre a deformidade física e a ameaça, levando, no entendimento de Canguilhem, ao desaparecimento do monstro:

Quando a monstruosidade se tornou um conceito biológico, quando as monstruosidades são repartidas em classes segundo relações constantes, quando se vangloriam de poder tê-las provocado experimentalmente, então o monstro é naturalizado, o irregular se rende à regra, o prodígio à previsão. $^{27}$

Por outro lado, Foucault acredita que a partir desse período a presença da monstruosidade não desaparece, mas passa a se dar no comportamento e não mais na aparência física. $\mathrm{O}$ autor observa essa mudança analisando a relação do monstro com o direito penal e o deslizamento da monstruosidade jurídico-natural para jurídico-moral. Foucault afirma que se até o século XVII-XVIII a monstruosidade como transgressão das regras das espécies naturais e suas distinções era associada a uma criminalidade possível, a relação se inverte a partir do século XIX: "haverá o que poderemos chamar de suspeita sistemática de monstruosidade no fundo de qualquer criminalidade. Todo criminoso poderia muito bem ser, afinal de contas, um monstro, do mesmo modo que outrora o monstro tinha uma boa possibilidade de ser criminoso"28.

[...] vemos que se esboça uma mudança, que é de certo modo a autonomização de uma monstruosidade moral, de uma monstruosidade de comportamento que transpõe a velha categoria do monstro, do domínio da alteração somática e natural para o domínio da criminalidade pura e simples. A partir desse momento, vemos emergir uma espécie de domínio específico, que será o da criminalidade monstruosa ou da monstruosidade que tem seu ponto de efeito não na natureza, mas no próprio comportamento. ${ }^{29}$ 
É importante notar que os autores estão tratando de monstros humanos. No entanto, se essas reflexões não dizem respeito aos monstros da fantasia, como vampiros, alienígenas ou zumbis, por exemplo, elas podem ser apropriadas para pensarmos sobre aqueles monstros da ficção que, embora sejam representações e não pessoas reais, inserem-se em um contexto ordinário, mais próximo do humano que do sobrenatural. Ou seja, em uma narrativa que se assenta em um universo ficcional mais próximo da experiência humana, as reflexões de Foucault e Wright podem ser elucidativas para explicar o conceito de monstruosidade na modernidade e, partindo delas, pensar na configuração de tais seres em narrativas que não coloquem em cena o extraordinário. A partir da noção de monstro moral podese enquadrar na categoria "monstro" personagens de narrativas cinematográficas como Coronel Kurtz, do filme Apocalypse Now, de Francis Ford Coppola, e Jack Torrance, de O iluminado, de Stanley Kubrick; assim como de narrativas literárias (sobre as quais nos deteremos aqui): como Fortunato, do conto "A causa secreta", de Machado de Assis, o protagonista de $O$ cheiro do ralo, de Lourenço Mutarelli e o personagem central dos contos "Passeio Noturno (Parte I)" e "Passeio Noturno (Parte II)", de Rubem Fonseca - mesmo que eles não apresentem em sua aparência elementos que os aproximem da monstruosidade física.

Vale observar que há uma considerável distância entre as narrativas da literatura brasileira das quais nos valeremos para construir nossa argumentação. O conto de Machado de Assis foi originalmente publicado em 1885, na Gazeta de Notícias, antes de ser agrupado em Várias Histórias, de 1896; as narrativas de Rubem Fonseca datam de quase um século depois, 1975, quando da publicação de Feliz ano novo; já o romance $O$ cheiro do ralo foi publicado em 2002, marcando o ingresso de Lourenço Mutarelli na literatura. Além das décadas que separam as narrativas, há, é claro, diferenças significativas com relação ao estilo dos autores: Machado de Assis e o seu realismo psicológico, Rubem Fonseca e a inauguração daquilo que Bosi chamou de "literatura brutalista", e um toque de experimentalismo que tempera a obra de Lourenço Mutarelli, que migrou dos quadrinhos para o romance há pouco mais de dez anos. A escolha por analisar aqui a monstruosidade em textos literários de autores tão díspares e distantes histórica, cultural e politicamente, se presta a mostrar como a figura do monstro moral pode estar presente em contextos diversos e, ainda assim, apresentar traços comuns.

No âmbito da monstruosidade moral, as características que envolvem tais criaturas sofrem algumas alterações. A impureza, por exemplo, não sendo mais visível na forma física do monstro, se expressa de maneira metafórica. Embora não haja mais a mistura de elementos físicos próprios a classes distintas, como 
30. CARROLL, Noël. A filosofia do horror ou os paradoxos do coração, 2000, p. 59. Carroll não considera a personagem Normal Bates como monstro, embora reconheça que ele é intersticial, porque, em seu conceito de horror artístico, são classificados como monstros apenas seres que não podem ser explicados pela ciência contemporânea. A personagem de Psicose é um esquizofrênico e, portanto, um ser que a ciência admite. Como aqui tomamos o conceito de monstro a partir de uma perspectiva mais ampla, nos valemos da explicação de Carroll sobre a impureza (psicológica) de Norman Bates para tratarmos de monstros morais.

31. FRANÇA, Julio. "O discreto charme da monstruosidade: atração e repulsa em 'A causa secreta', de Machado de Assis", Vitória da Conquista, 2012, p. 50.

32. MUTARELLI, Lourenço. O cheiro do ralo, 2011, p. 19. a confusão de humano e animal no caso de seres como as sereias - misto de mulher e ave ou peixe -, ainda se faz presente no monstro moral a violação de categorias, ponto central da impureza monstruosa. Essa inadequação, no entanto, pode se apresentar associada ao monstro, mas não é aparente. Esse é o caso, por exemplo, da personagem Norman Bates:

Ele é Nor-man; nem homem nem (nor) mulher, mas ambos. É filho e mãe. É o vivo e o morto. É tanto a vítima quanto o algoz. É duas pessoas em uma. Ou seja, é anormal, porque é intersticial. No caso de Norman, isso se deve mais à psicologia do que à biologia. Contudo, ele é um poderoso ícone da impureza. ${ }^{30}$

Aquilo que á antinatural no monstro também pode estar relacionado às nossas expectativas com relação ao comportamento humano. Como exemplo, o comportamento de Fortunato no conto de Machado de Assis transgride o que se espera no que diz respeito aos sentimentos humanitários: "Seu sadismo é visto por Garcia como uma degeneração do que significa ser humano, uma quase violação dessa categoria" ${ }^{31}$.

Em $O$ cheiro do ralo, o título do romance exerce uma função importante no que diz respeito à leitura da impureza do narrador-personagem. Desde o início da narrativa, o cheiro que exala do ralo do banheiro da loja de penhores do protagonista infesta o ambiente. A personagem demonstra receio de que os clientes pensem que o cheiro provém dela - " "[...] Eu não me importo com ninguém. Só não quero que eles pensem que o cheiro do ralo é meu"32. De fato, essa preocupação, verbalizada pela personagem, nos leva à sua associação com o cheiro proveniente do ralo. Além disso, a fala de um dos fregueses corrobora essa leitura:

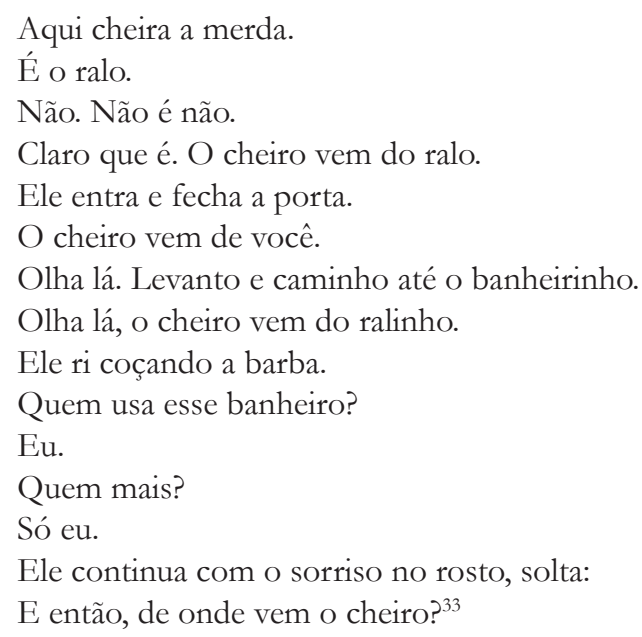

A associação do narrador com o cheiro do ralo, que perpassa toda a narrativa, dá a conhecer o componente impuro do 
monstro. O resíduo orgânico das fezes (e seu odor) coloca em cena a intersticialidade dentro/fora, eu/não eu que compõe a monstruosidade da personagem.

Com a atualização da impureza, que já não se revela na aparência física, a ameaça do monstro é intensificada. Isso porque agora a monstruosidade é invisível. Enquanto havia um senso de segurança na monstruosidade que podia ser apontada no corpo do outro, a falta de sinais aparentes que permitam uma identificação à primeira vista é atemorizante porque, posicionando o monstro moral muito mais próximo do humano, aumenta o sentimento de imprevisibilidade ${ }^{34}$. Quando o monstro não corporifica a diferença, como reconhecê-lo e prevenir-se de seus ataques?

Outro componente da monstruosidade, o espaço geográfico, também passa por mudanças nesse outro universo. Para pensar o novo habitat do monstro, levaremos em conta alguns apontamentos de Luiz Nazário. O autor identifica uma nova configuração de monstruosidade, que deriva do avanço da ciência: os "monstros tecnológicos - objetos mecânicos, eletrônicos e genéticos, animados sob as formas mais variadas" 35 . O raciocínio que o leva a explicar o surgimento deste tipo de seres está intimamente vinculado a questões espaciais:

[...] num mundo inteiramente devastado, onde o homem trabalhando conseguiu ocupar todos os espaços selvagens, deslocando os monstros de seus antigos habitats, [...] [o]s monstros modernos não são mais organismos selvagens do Além, criaturas da natureza exótica, matérias vivas desconhecidas; eles assustam como objetos fabricados pelo próprio homem no seio da civilização.

[...]

Agora, a humanidade caminha para a civilização total do planeta, sem espaço para os mistérios da Natureza interior e exterior ao homem. Tudo se devassa e se interliga, através das redes de transporte, comunicação e exploração. Contudo, mesmo integralmente civilizada, a Terra permanece inóspita. Os monstros continuam vivos, ainda que não possam mais ser ingenuamente identificados à Natureza ignota e inexplorada. ${ }^{36}$

Partimos da constatação de Nazário sobre o espaço do monstro para uma conclusão ampliada. Se é verdade que o espaço ermo, inóspito e selvagem que antes constituía o domínio do monstruoso já não existe, o monstro pode, por um lado, como conclui Nazário, se apresentar sob a forma de seres tecnológicos criados pelo homem; por outro lado, entendemos que esse deslocamento do monstro para "dentro" da civilização pode indicar que ele a cada momento tem se tornado mais humano. O mesmo movimento de expansão do conhecimento que, por meio da nomeação e classificação, deslocou a monstruosidade
34. Richard Kearney identifica essa noção de imprevisibilidade no monstro moderno em relação com a aparência física. $\mathrm{O}$ autor aponta a existência de uma não conformação ao que se espera no que diz respeito a monstros que escondem seu horror sob uma máscara de beleza, como, por exemplo, o típico vampiro-sedutor, ou Bin Laden, que pode ser considerado um homem bonito apesar de seu discurso. Nós partimos de suas conclusões e as ampliamos para pensar no aumento do horror provocado pelos monstros morais: monstros invisíveis, que não podem ser identificados visualmente, pois parecem "pessoas normais", apesar de seu comportamento.

35. NAZÁRIO, Luiz. Da natureza dos monstros, 1998, p. 59.

36. Ibidem, p. 59-60. 
37. STOKER, Bram. Drácula, 2014, p. 80-81.

38. SHELLEY, Mary.

Frankenstein ou o Prometeu moderno, 2011, p. 123.

39. Ibidem, p. 129. da aparência física para o comportamento, quando se aplica ao habitat, aproxima geograficamente o monstro cada vez mais da humanidade.

O monstro moderno já não assume a mesma posição que ocupavam os monstros da tradição literária. O conde Drácula age como o ser de fronteira que desejava invadir a Inglaterra e integrar-se. Para isso, ele deseja eliminar os sinais de diferença que o marcam como estrangeiro, adquirindo conhecimento e eliminando seu sotaque:

Desejo ardentemente andar pelas ruas apinhadas de sua portentosa cidade; estar em meio ao vórtice e à fúria da impetuosa humanidade; partilhar de sua vida, de suas mudanças, de sua morte, e de tudo aquilo que faz de Londres uma gloriosa metrópole. Mas, ai de mim! Até agora, só conheço sua língua por meio dos livros. Conto com você, meu caro amigo, para aperfeiçoar minha fala.

$[\ldots]$

Bem sei que, se me mudasse hoje para Londres, todos lá saberiam imediatamente que sou um estrangeiro. E isso não serve para mim. [...] [E]u aceitaria me tornar um anônimo, alguém igual a todos os outros, um ser perdido na multidão. Mas o que não posso tolerar é que alguém, ao falar comigo em uma rua de Londres, detenha-se subitamente e, com um riso de escárnio, exclame: "Vejam só, um forasteiro!". Não, isso jamais. ${ }^{37}$

A criatura de Victor Frankenstein, à qual se negou a vida social e a história, aparece na narrativa situada à margem, do lado de fora e desejando integrar-se, fazer parte da sociedade. O locus de exclusão do monstro pode ser percebido pelo refúgio em que se abriga aos fundos na cabana da família DeLacey. A partir desse espaço, situado fora da habitação, o monstro observa por uma fresta os hábitos da família (dentro) e adquire a competência da comunicação e conhecimentos sobre história. A criatura planeja com esperança uma futura integração naquele ambiente familiar: "eu ansiava em me reunir a eles" 38 :

Desenhei mentalmente milhares de quadros em que eu me apresentava a eles e tentava antecipar sua recepção. Supunha que seriam tomados pela repugnância, até que, com minha conduta mansa e minhas palavras conciliatórias, eu conquistasse primeiro a simpatia e depois seu amor. ${ }^{39}$

Os monstros modernos, no entanto, já não se encontram do lado de fora da fronteira, desejando entrar. Eles habitam o mesmo espaço geográfico que os humanos, levando a uma horrível conclusão: os monstros não apenas se parecem conosco, eles estão entre nós.

O narrador-personagem dos contos "Passeio Noturno (Parte I)" e "Passeio Noturno (Parte II)", de Rubem Fonseca, 
por exemplo, longe de se situar em um espaço periférico, marginal, ou ermo e desconhecido, levando-se em conta sua posição social, habita provavelmente uma região privilegiada na cidade do Rio de Janeiro. As indicações do texto literário, como o jantar servido à família à francesa pela copeira e o Jaguar que "custou uma fortuna" nos levam a presumir sua condição abastada. A situação financeira do protagonista e o carro que dirige - que, em suas próprias palavras, o complementa - atrai Ângela que, concentrando-se nas aparências, não pode supor o perigo de tal aproximação. O espaço que o protagonista dos contos habita não é indicativo de sua condição monstruosa. Pelo contrário, o lugar social que ele ocupa mascara ainda mais sua monstruosidade. Inserido em um contexto não apenas geográfico, como familiar e profissional que, a princípio, atesta uma situação de normalidade, o monstro moral dessas narrativas não deixa vislumbrar sua condição de diferença.

Nesse deslocamento em direção ao humano, o poder característico da monstruosidade, mesmo que não esteja mais associado ao sobrenatural, ainda existe. Como vimos, Alexa Wright identifica a presença desse elemento em monstros como serial killers, a quem ela caracteriza como onipotentes, e imputa a esse atributo a fascinação que tais figuras provocam. Em monstros morais, o poder se apresenta intimamente relacionado à ausência de limitações, à liberdade que a falta de vínculos afetivos e sociais proporciona. Tendo a obtenção de prazer como única regra a que deve obediência, o monstro moderno torna-se extremamente poderoso, porque livre.

No protagonista de $O$ cheiro do ralo, a presença desses três elementos - prazer, poder e liberdade - advêm do poder aquisitivo e da maneira como ele conduz seu negócio. $O$ fato de ele não vender nada e comprar apenas aquilo que deseja e não aquilo que precisa, determinando o valor dos objetos tomando como base caprichos e crueldades, revela a situação de poder em que se coloca e a liberdade e o prazer que norteiam seus negócios. Na sua loja de quinquilharias, é ele quem determina as regras do jogo e cabe àqueles que adentram seu estabelecimento se sujeitar a essas normas, caso desejem vender seus objetos:

Traz umas bolachas do Gardel.

Coisa fina. Diz ele.

Tá, põe aí. Tiro as notas.

Isso é muito pouco!

Então pega e leva de volta.

Não. Não pode ser assim. Isso é jóia rara. É só o senhor dobrar o valor. Não dobro.

Não dobro e se quiser, agora dou só a metade do preço que acabei de fazer.

Mas isso não está certo, doutor.

Isso, fui eu que inventei. 
40. MUTARELLI, Lourenço.

O cheiro do ralo, 2011, p. 28.
42. ASSIS, Machado de. "A causa secreta”, 1999, p. 118-119.

\section{Eta! Inventou o quê?}

A certeza. ${ }^{40}$

Os motivos que orientam o julgamento de valor dos objetos que se lhe oferecem não se baseiam no valor comercial das peças, mas se apoiam no arbítrio do comerciante, e, em algumas ocasiões, a decisão de comprar ou não os objetos oferecidos tem como fundamento único o prazer que o sofrimento alheio lhe proporciona:

Entra outro. Traz uma pesada Olivetti. Tem até o manual original. Línia 98, instrucciones para uso. Eu adoro fazê-los voltar quando trazem coisas pesadas.

Ah, não! Outra dessas não!

Ai. Não me diga que o senhor já tem muitas dessas?

Uma sala cheia.

Ai, meu Deus do céu. E agora?

Sinto muito. Você veio de carro?

Carro?! Que nada. Vim de ônibus.

YES!!! Vibro por dentro.

Tive que pedir pro cobrador deixar eu subir por trás.

Você sabe, né, senão como eu ia passar pela catraca?

Puxa, sinto muito. Só pra piorar, solto.

Olha, te juro, se tivesse uma dessas a menos, eu até que podia pegar essa sua. Mas... tsc, tsc, tsc...

Hoje eu sou mais eu.

Grito bem alto:

PRÓXIMO!!! ${ }^{41}$

Uma característica dos monstros que se mantém inalterada é a reação mista que eles provocam. Os monstros continuam despertando ao mesmo tempo emoções ambivalentes como medo e atração, independentemente do contexto cultural e histórico em que apareçam.

Em "A causa secreta", a sensação que Fortunato desperta em Garcia no episódio em que aquele se dedica a ajudar Gouveia, o empregado do arsenal de guerra ferido, é descrita como sendo "de repulsa ao mesmo tempo que de curiosidade". Essa ambivalência afetiva é reforçada pela atitude de desdém e humilhação com que Fortunato recebe o agradecimento do homem ferido, despertando em Garcia assombro e também interesse:

Tudo isso assombrou o Garcia. Este moço possuía, em gérmen, a faculdade de decifrar os homens, de decompor os caracteres, tinha o amor da análise, e sentia o regalo, que dizia ser supremo, de penetrar muitas camadas morais, até apalpar o segredo de um organismo. Picado de curiosidade, lembrou-se de ir ter com o homem de Catumbi, mas advertiu que nem recebera dele o oferecimento formal da casa. ${ }^{42}$

Por fim, quando a monstruosidade de Fortunato é revelada em sua plenitude a Garcia, que assiste ao amigo torturando um 
rato, o médico, cuja primeira reação é desviar os olhos diante da cena, consegue "dominar a repugnância do espetáculo para fixar a cara do homem. Nem raiva, nem ódio; tão somente um vasto prazer, quieto e profundo, como daria a outro a audição de uma bela sonata ou a vista de uma estátua divina" ${ }^{\text {"43 }}$.

\section{Monstros: identidade e alteridade}

Os monstros não são construídos apenas pela combinação de elementos que dão configuração a seu "corpo" (seja no sentido literal, no caso do monstro físico, seja no sentido figurado, quando se trata do monstro moral). Além de descrever como o monstro é, suas características, é preciso entender o significado de sua presença, a função que ele exerce. Daí a afirmação de Cohen de que o monstro se constrói por meio de duas narrativas: uma que dá a conhecer a forma como ele se apresenta, e outra - sobre a qual nos deteremos agora - que põe em cena seu significado, sua razão de existir.

Os monstros se identificam "por um aviso ou um castigo por alguma ruptura de um código - por um mal cometido" ${ }^{44}$. Segundo Gilmore, o monstro é uma metáfora de tudo aquilo que deve ser repudiado pelo espírito humano. A monstruosidade encarna uma ameaça existencial à vida social: "the caos, atavism, and negativism that symbolize destructiveness and all other obstacles to order and progress, all that which defeats, destroys, draws back, undermines, subverts the human project" ${ }^{\prime 2}$. Por tudo o que ele representa, o monstro constitui o avesso de um modelo a ser seguido e, portanto, sujeito a uma manobra que delimita fronteiras, estabelecendo proibições para alguns comportamentos e valorizando outros. O monstro, como "[f]orma extrema de alteridade, [...] é sempre definido a partir de uma comunidade de não-monstros"46. Ele é "[...] o outro, o estranho, o estrangeiro, o 'inimigo natural' pronto a encarnar o Mal e contaminar, com sua simples presença, a humanidade" ${ }^{47}$. Essa sua condição de "diferença", faz do monstro um alerta contra o risco de ultrapassar fronteiras.

O monstro [...] existe para demarcar os laços que mantêm unido aquele sistema de relações que chamamos cultura, para chamar atenção - uma horrível atenção - a fronteiras que não podem - não devem - ser cruzadas. [...] Como uma espécie de pastor, [...] delimita o espaço social através do qual os corpos culturais podem se movimentar. ${ }^{48}$

A figura do monstro é um instrumento regulador, assim como está intimamente associada à noção de identidade, uma
43. Ibidem, p. 123.

44. JEHA, Julio. "Monstros como metáfora do mal", 2007, p. 22.

45. GILMORE, David D.

Monsters: evil beings mythical beasts and all manners of imaginary terror, 2003, p. 12.

46. NAZÁRIO, Luiz. Da

natureza dos monstros, 1998, p. 29.

47 Ibidem, p. 285.

48. COHEN, Jeffrey. "A cultura dos monstros: sete teses", 2000, p. $42-43$. 
49. TUCHERMAN, Ieda. Breve história do corpo e de seus monstros, 1999 , p. 83.

50. KEARNEY, Richard.

Strangers, gods and monsters: interpreting otherness, 2003, p. 117.

51. WRIGHT, Alexa. Monstrosity: the human monster in visual culture, 2013, p. 17.

52. Crick, apud. WRIGHT, Alexa. Monstrosity: the human monster in visual culture, 2013, p. 18.

53. SHILDRICK, Margrit. Ebodying the monster: encounters with the vulnerable self, 2002, p. 5.

54. BEAL, Timothy K. Religion and its monsters, 2002, p. 196.

55. WRIGHT, Alexa. Monstrosity: the buman monster in visual culture, 2013, p. 112.

56. Theodore Robert Cowell, mais conhecido como Ted Bundy, foi um assassino em série que matou mais de trinta mulheres por toda América entre os anos de 1974 e 1979. Ele foi condenado em 1979 e, após dez anos no corredor da morte, foi executado por eletrocussão em janeiro de 1989. vez que "o processo que estabelece identidade é o que demarca uma fronteira entre o que é idêntico (mesmo) e o que é diferente (outro)"49. Segundo Kearney, "monsters are our Others par excellence. Without them we know not what we are. With them we are not what we know" 50 .

Os monstros refletem os valores culturais que transgridem a ordem social, moral e ontológica de uma sociedade particular, sendo, portanto, considerados como “outros". Segundo Wright, eles são uma expressão da diferença que funciona como elemento definidor do eu e das normas sociais por meio da manifestação daquilo que é considerado inaceitável, e por isso estão associados às noções de "outro" e "alteridade". No entanto, essa alteridade - essencial para a formação da identidade - nunca é da ordem do dado, e sempre do construído. "In other words, the subjective position of the observer is always implicated in the construction of the 'other', whether monstrous or not"51.

Assim como a identidade é uma construção e, portanto, dinâmica e mutável, também o é a alteridade: "[...] a change in the value of the 'self', invariably alters the image of the other and vice versa; and either change alters the nature of the difference which they constitute and by which they are constituted... there can be no final definition of the relation between 'ourselves' and 'others"' 52 .

Levando em conta que a alteridade que constituiu o monstruoso nada mais é do que uma construção, um discurso, é possível entender que o monstro não é de fato tão "outro" assim:

[... what is at stake in a politics of identity and difference is the security of borders that mark out the places which are safe and which are unsafe, and who is due to moral consideration and who is not. But despite the foundation claims, those boundaries are never finally secured, not because the claims of the excluded may become too insistent to resist, but because exclusion itself is incomplete. ${ }^{53}$

Segundo Beal, os monstros não podem ser simplesmente uma imagem negativa do nosso mundo ou de nós e talvez o que mais amedronte seja o fato de que nós nos enxergamos neles. "Monsters blur lines between inside and outside, this wordly and otherworldly, self and other" ${ }^{54}$. O reconhecimento de que a diferença que constitui a monstruosidade não é tão estável ou definitiva quanto se supunha aproxima o monstro do humano. Principalmente quando se trata do monstro moral, que não pode ser visualmente identificável: "This type of monstrosity is not readily accessible to the gaze. It resists visual representation, is difficult to regulate and, most disturbingly, difficult to categorize as 'other' in terms of social or medical pathology" 55 .

É esse ponto que Alexa Wright levanta quando, analisando a figura do serial killer como monstro, discute a posição de celebridade que o assassino Ted Bundy ${ }^{56}$ adquire na mídia: 
Despite his appearance of normality, Bundy was a highly transgressive figure, not only on account of the monstrous acts he performed, but also as a result of the way in which he blurred the boundaries between monstrous 'other' and the norm. The moral uncertainty generated by the contradictions between Bundy's physical appearance, his apparently 'normal' behavior and the narratives of deviance attached to him undermines any attempt to identify him as categorically 'other', completely different to 'us', normal people.

$[\ldots]$

It seems that there is a universal need to believe that criminal monsters such as Bundy are categorically different, and yet in this case the evidence fails. When the suspect looks normal it is difficult to set a clear and tangible boundary between 'really' normal people and someone who has been identified as a criminal monster. [...] The traditional notion of the monster as recognizably alien 'other', physiognomically marked by insanity or evil, and therefore clearly separable from the 'normal' subject is no longer relevant in the face of figures such as Bundy. ${ }^{57}$

Apesar das tentativas de identifica-lo como absolutamente diferente, há uma proximidade que faz do monstro uma parte de nós. "[N]ão é a oposição simples que marca a diferença entre monstro e homens, mas um sistema complexo de aproximação e distância" ${ }^{\prime 58}$. O monstro perturba a ordem e as normas, trazendo à luz a fragilidade dos alicerces que sustentam as separações binárias: nós/eles, civilização/bestialidade, humanidade/monstruosidade.

\section{Referências}

ASSIS, Machado de. "A causa secreta". In: . Contos. São Paulo: Objetivo, 1999.

BEAL, Timothy K. Religion and its monsters. New York; Oxon: Routledge, 2002.

CANGUILHEM, Georges. "A monstruosidade e o monstruoso". In: O conbecimento da vida. Tradução

de Vera Lucia Avellar Ribeiro. Rio de Janeiro: Forense Universitária, 2012. p. 187-202.

CARROLL, Noël. A filosofia do horror ou os paradoxos do coração. Tradução de Roberto Leal Ferreira. Campinas: Papirus, 1999.

COHEN, Jeffrey. "A cultura dos monstros: sete teses". In: SILVA, Tomaz Tadeu da (Org.). Pedagogia dos monstros.
57. WRIGHT, Alexa. Monstrosity: the human monster in visual culture, 2013, p. 155.

58. TUCHERMAN, Ieda. Breve bistória do corpo e de seus monstros, 1999 , p. 78. 
Os prazeres e os perigos da confusão de fronteiras. Tradução de Tomaz Tadeu as Silva. Belo Horizonte: Autêntica, 2000. p. 23-60.

FONSECA, Rubem. "Passeio Noturno (Parte I)". In: 64 contos de Rubem Fonseca. São Paulo: Companhia das Letras, 2004a.

. "Passeio Noturno (Parte II)". In: .64 contos de

Rubem Fonseca. São Paulo: Companhia das Letras, 2004b.

FOUCAULT, Michel. Os anormais: curso no Collège de France (1974-1975). Tradução de Eduardo Brandão. São Paulo: Editora WMF Martins Fontes, 2010.

FRANÇA, Julio. "O discreto charme da monstruosidade: atração e repulsa em 'A causa secreta', de Machado de Assis". Vitória da Conquista, v. 1, n. 2, p. 46-53, 2012.

GILMORE, David D. Monsters: evil beings, mythical beasts, and all manners of imaginary terror. Philadelphia: University of Pennsylvania Press, 2003.

JEHA, Julio. "Monstros como metáfora do mal". In: JEHA, Julio (Org.). Monstros e monstruosidades na literatura. Belo Horizonte: Editora UFMS, 2007. p. 9-31.

KEARNEY, Richard. Strangers, gods and monsters: interpreting otherness. London; New York: Routledge, 2003.

MUTARELLI, Lourenço. O cheiro do ralo. São Paulo: Companhia das Letras, 2002.

NAZÁRIO, Luiz. Da natureza dos monstros. São Paulo: Arte \& Ciência, 1998.

SHELLEY, Mary. Frankenstein ou o Prometeu moderno. Tradução de Adriana Lisboa. Rio de Janeiro: Nova Fronteira, 2011.

SHILDRICK, Margrit. Embodyind the monster: encounters with the vulnerable self. London, Thousand Oaks, New Delhi: SAGE Publications, 2002.

STEVENSON, Robert Louis. O médico e o monstro. Tradução de José Paulo Golob, Maria Ângela Aguiar e Roberta Sartori. Porto Alegre: L\&PM, 2011.

STOKER, Bram. Drácula. Tradução de José Francisco Botelho. São Paulo: Penguin Classics Companhia das Letras, 2014.

TUCHERMAN, Ieda. Breve história do corpo e de seus monstros. Lisboa: Ed. Vega, 1999.

WRIGHT, Alexa. Monstrosity: the human monster in visual culture. London; New York: I. B. Tauris, 2013. 